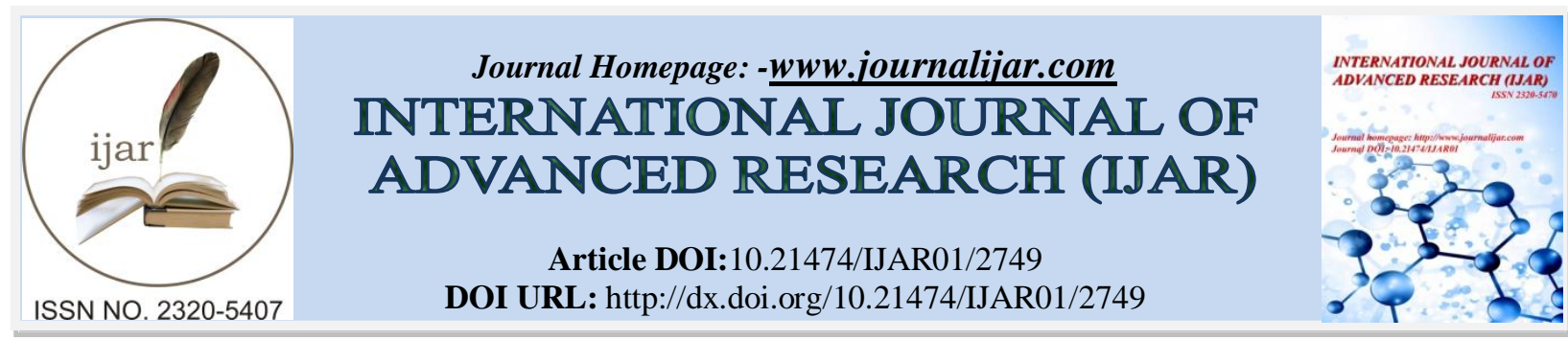

RESEARCH ARTICLE

\title{
Effect of Balance Training on Postural Control and Risk of fall in Stroke Patients.
}

\section{HeshamGalal Mahran ${ }^{1}$, EmadTawfik Ahmed ${ }^{2}$, Shamekh Mohammed El-Shamy ${ }^{1}$ and Amir Abdel-Raouf El- Fiky $^{3}$.}

1. Department of Physical Therapy, Faculty of Applied Medical Sciences, Umm Al-Qura University, Saudi Arabia.

2. Department of Physical Therapy, Faculty of Applied Medical Sciences, Taif University, Saudi Arabia.

3. Department of Physical Therapy for Neuromuscular Disorders and Its Surgeries, Faculty of Physical Therapy, Cairo University, Egypt.

\section{Manuscript Info}

Manu......................

History

Received: 15 November 2016

Final Accepted: 17 December 2016

Published: January 2017

Key words:-

Balance training, biodex balance system, visual feedback, stroke.

\begin{abstract}
Background: Purpose of this study was to investigate of effect of visual feedbackbalance training on postural control and risk of fall in stroke patients.

Methods: Forty stroke patients were included in this study. Their age ranged from40-60 years. They were evaluated using the Biodex Balance System pre and posttreatment. They were divided intotwo equal groups (control group and study groups).Subjects in both groups participated in the conventionalstroke rehabilitationprogram, one hour /day/ 5 days/week $/ 3$ successive monthsin addition, subjects in thestudy group received a $20 \mathrm{~min}$ of balance training once daily,five days a week for 3 months using the Biodex Balance System (BBS).

Results: Significantimprovements in balance training measurements were found in thetrained group at 3 months after completing the training program.

Conclusion:Patients in thevisual feedback balance training group had significant improvements whencompared with the control group in term of improving of postural control anddecreasing of risk of fall. The results showed that balance training was beneficial forpatients after hemiplegic stroke.
\end{abstract}

Copy Right, IJAR, 2016,. All rights reserved.

\section{Introduction:-}

Stroke is a form of cardiovascular disease affecting the blood supply to the brain. Also referred to as cerebrovascular disease. In stroke, there has been a disturbance in brain function, often permanent, caused by either a blockage or a rupture in a vessel supplying blood to the brain [1].Stroke is a common neurological disorder, the second commonest overall cause of death, and a major cause of disability in survivors. [2]. Stroke is the leading cause of serious long-term disability, with over 1 million adults reporting difficulties in function as a result of stroke. In addition to the primary deficits associated with stroke, there is a high rate of secondary complications, including falls [3].

Corresponding Author:-Hesham Galal Mahran.

Address:-Department of Physical Therapy, Faculty of Applied Medical Sciences, Umm Al-Qura University, Saudi Arabia. 
Balance problems in hemiplegic patients after stroke can be caused by different impairments in the physiological systems involved in postural control, including sensory afferents, movement strategies, biomechanical constraints, cognitive processing, and perception of verticality [4].

Clinical and laboratory evaluation in hemiparetic patients can show the asymmetrical distribution of weight in the lower limbs, with deviation of the center of mass to the uninvolved side, difficulty in actively transferring and keeping the center of mass in the hemiparetic side in the lateral and anterior directions and decreased frontal plane stability, impaired muscle selection with consequent increase in body oscillations during standing. Hemiparetic stroke patients may present difficulties in weight transfer from the affected to the unaffected side [4]. Postural sway for patients with hemiplegia can be twice that of their age-matched peers. hemiplegia can cause a reduction in patients' limits of stability, which is defined as the maximal distance that an individual can shift his or her weight in any direction without loss of balance [5].

To maintain balance in activities of daily living (ADL), posture control is essential, while motor, sensory and higher brain cognitive faculties all contribute to postural control [6-8]. Following a stroke, patients lose functions of the motor, sensory and higher brain cognitive faculties to various degrees which lead to diminished balance. [9-10]. The Biodex balance system (BBS) is an important valid and reliable balance assessment and therapeutic tool. It can be used for evaluating and training of patients with balance deficits as it includes many training and testing programs simultaneously. These assessment programs include Dynamic limits of stability (DLS), fall risk tests and others [11].

The Biodex Balance System has been used to evaluate postural balance in recent years. The BBS is a multi-axial device that objectively measures and records an individual's ability to stabilize the involved joint under dynamic stress. It uses a circular platform that is free to move in the anterior-posterior and medial-lateral axes simultaneously [12]. BBS allows up to $20^{\circ}$ of foot platform tilt, which permits the ankle joint mechanoreceptors to be stimulated maximally. The BBS measures, in degrees, the tilt about each axis during dynamic conditions and calculates a medial-lateral stability index (MLSI), anterior-posterior stability index (APSI), and an overall stability index (OSI). These indexes represent fluctuations around a zero point established prior to testing when the platform is stable [13]. As far as we know, only a few studies have mentioned about the effects of visual feedback balance training for stroke patients using the Biodex balance system. Therefore, in this study, we evaluated the effects of this training program on postural control and risk of fall in stroke patients.

\section{Methods:-}

\subsection{Subjects:-}

Forty stroke patients included in the study. Their age ranged from 40-60 years old. They were selected from al-Noor specialized hospital in Makkah. Inclusive criteria: Patients were required to meet the following criteria for inclusion in the study: (1) approximately 3 months or more after initial onset of an ischemic cerebrovascular accident (thrombotic and embolic stroke), (2) ability to understand and follow simple verbal instructions, (3) ambulatory before the stroke, (4) ability to stand with or without assistance and to take at least one or more steps with or without assistance, (5) no medical contraindication to walking. Exclusive criteria: Patients were excluded if they had a history of any other neurological pathology, conditions affecting balance, dementia, impaired vision or conscious levels or concomitant medical illness or musculoskeletal conditions affecting the lower limbs. All recruited patients were randomly assigned into two equal groups; control group and trained group. They were evaluated and treated in the laboratory of Physical Therapy Department, Faculty of Applied Medical Sciences, Umm Al-Qura University.

\subsection{Intervention:-}

\subsubsection{Measurement:-}

Biodex Balance System SD: (BBS; Biodex Inc., Shirley, NY) was used as a valid and reliable equipment for performing Dynamic limits of stability and fall risk test. It consists of support handle, platform, display and printer. It has a static mode and 12 levels of dynamic platform tilt (static, 12 is more stable, 1 is less stable) as shown in figure (1). This balance system was used for assessment of the changes in reactive postural balance control for the participated patients from standing position pre and immediately post training.

All participating were given several explanatory sessions before the evaluation process. During the evaluation, each patient was asked to stand bare feet in the center of platform while both arms at the side of the body and to look 
straight and focus on visually feedback screen. They were tested on static level. Three trials were performed and the average of them was calculated.

The Support handles were adjusted and the evaluator stood close beside the patient to provide assistance in case of balance lossas shown infigure (2).

For postural stability testing, the overall stability index (OASI), mediolateral stability index (MLSI) and anteroposterior stability index (APSI) were obtained for the 40 patients by doing a test at static levelfor 20 seconds, with eyes open. The patients were asked for keeping the centre of pressure in the centre of a target displayed on the monitor. Patientsnot allowed to support themselves with their hands. Before the test, the patients did one training test. It was performed as a single test to reduce the potential effects of learning and fatigue as shown in figure (3:A\&B).

Test results were automatically compared to age dependent normative values stored in the higher risk of falling which is an indicator of poor balance. Lowering of this score post-training to be nearby normative values is a strong evidence for reactive balance control improvement.

\subsubsection{Treatment:-}

Subjects in both the experimental (A) $(n=20)$ and the control group (B) $(n=20)$ participated in our conventional stroke rehabilitation program, 5 days a week, one hour /day, for three successive months. The conventional program consisted of neurodevelopmental facilitation techniques, positioning, range of motion and progressive resistive exercises, together with training in endurance, walking and activities of daily living. Postural control exercises included maintenance of standing and shift of the weight loaded to the paretic side. Therapists combined elements of Brunnstrom's movement therapy, Bobath neurodevelopment treatment and proprioceptive neuromuscular facilitation techniques according to the patients' needs and performance. This personalized rehabilitative care was designed to help the patient to perform the daily activities of living independently in order to achieve the best possible quality of life.In addition to conventional program, the experimental group received $20 \mathrm{~min}$. of balance training once daily, five days a week for three months using the Biodex Balance System (BBS). Subjects encouraged to maintain their posture steadily and symmetric weight bearing while adapting to different static sensory conditions through verbal or tactile cues. For dynamic function training, the patients were instructed to practice controlling their weight shifts by tracing the moving targets on the screen in every main direction [14].

The postural balance control training routine for group (A) was conducted in the form of postural stability training in every session through the usage of the Biodex balance system. The training program required the patient to perform training while standing bare feet in the same body position used during testing and followed the same instructions on the evaluation process for postural stability during every training sessionas shown in figure (4B).

Weight shift training session consisted of three trials with five minutes rest between them. In each trial, the patient would complete the task requirements. Then each patient received $10 \mathrm{~min}$ rest before the application of the traditional training program for one houras shown in figure (4A). 


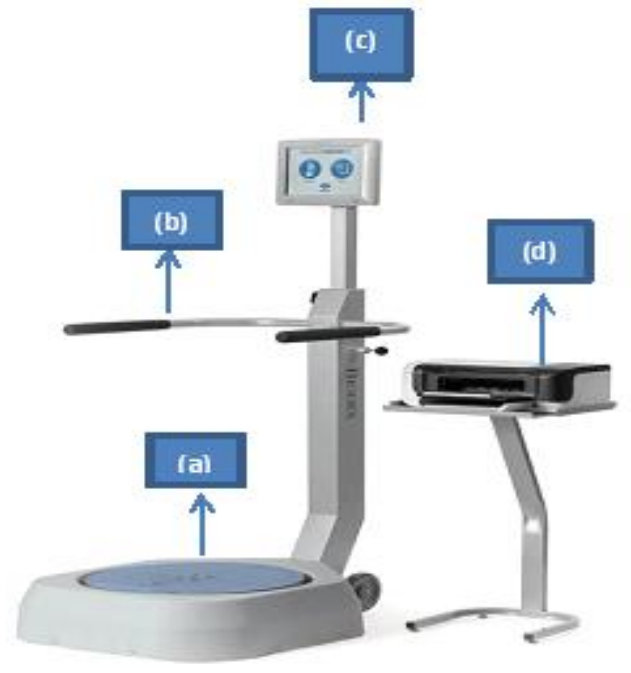

Figure 1: Biodex stability system.

(a) A movable balance platform, (b) Support rails, (c) Display and (d) Printer

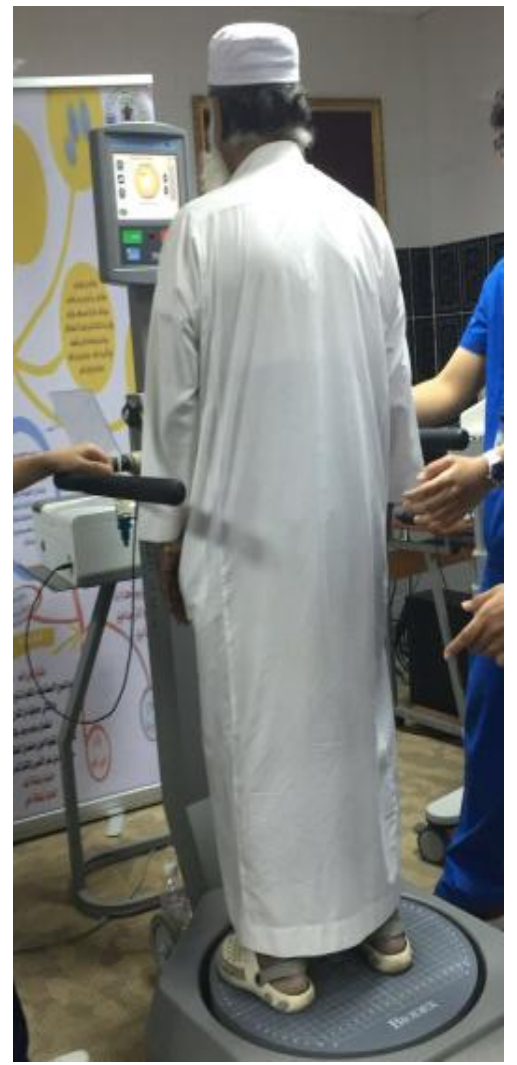

Figure2: Patient Preparation on biodex platform for evaluation and training 


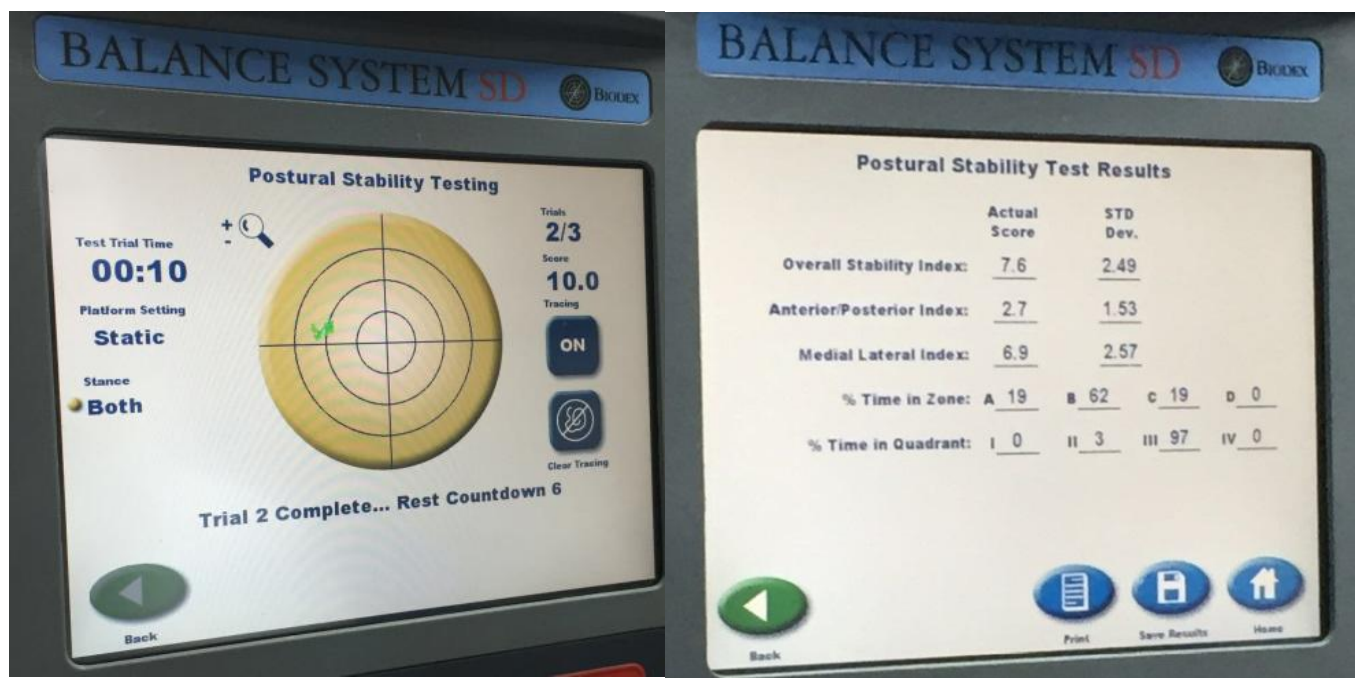

(A)
(B)

Figure 3: A) -Patient's postural stability test screen shot. B) - Patient's postural stability test results screen shot

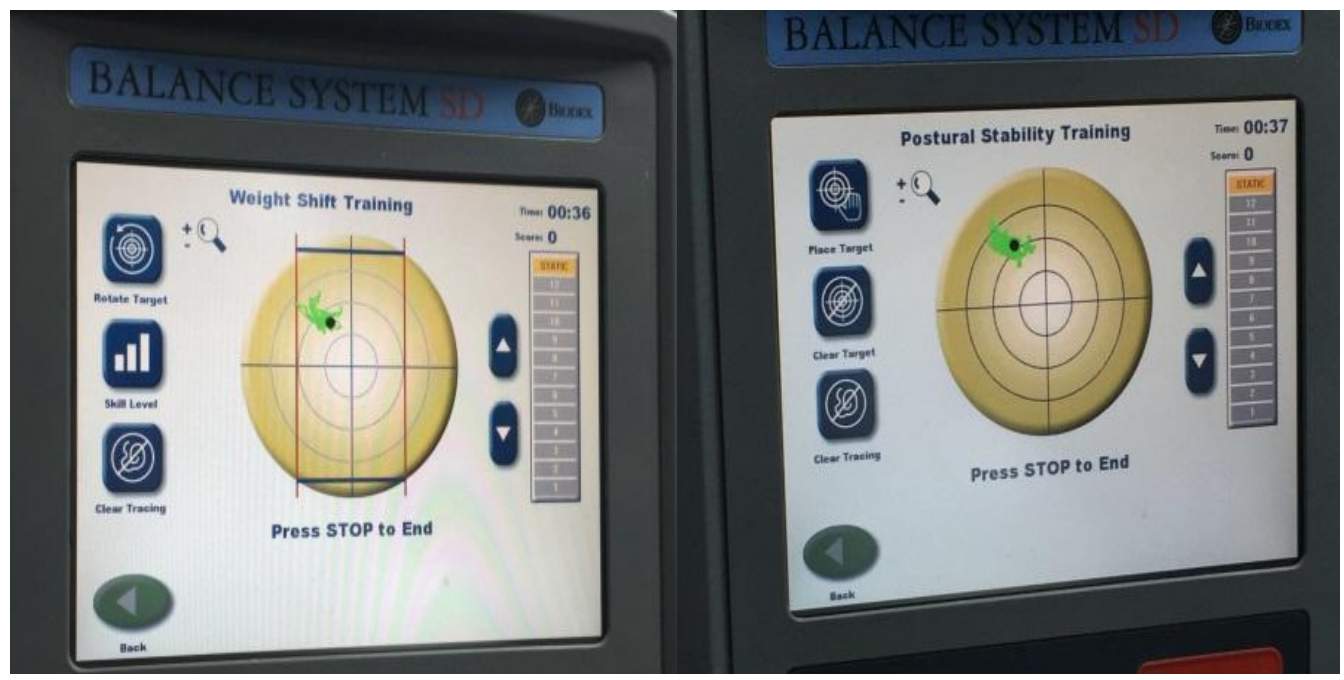

(A)

(B)

Figure 4:A)- Patient's weight shift training screen shot. B) - Patient's postural stability training screen shot

\subsection{Data analysis and statistics:-}

Data were pooled across subjects according to group (control group and trained group). Differences in the continuous data (age, body weight, and body height) between groups were compared using an Independent sample $t$ test. Comparison between pre- and immediately post-treatment in each group was performed using paired t-test. While the comparison between both groups pre and immediately post treatment was carried out by using an unpaired t-test. SPSS computer program version 16.00 (SPSS Inc., Chicago, IL) was used for data analysis. p Value less to 0.05 was considered significant.

\section{Results:-}

Forty stroke patients randomly distributed into two equal groups were participating in this study. The demographic characteristics of the included patients were illustrated in Table 1 . The mean age of study group was (52.9 6.08$)$ while the mean age of control group was $(51.25 \pm 6.71)$, the mean of weight as well as the mean of height for study group were $(74.9 \pm 7.75 \mathrm{~kg})$ and $(175 \pm 6.43 \mathrm{~cm})$ respectively while the mean of weight as well as the mean of height for control group were $(73.5 \pm 7.15 \mathrm{~kg})$ and $(172 \pm 6.0 \mathrm{~cm})$ respectively and a mean time from stroke onset was ( $9.6 \pm 1.9)$ months for study group while it was $(9.45+1.73$ ) for control group , (see Table 1). And there were no significant difference between two groups regarding to patient's age, weight, height, and time of stroke onset as $\mathrm{p}$ value $>(0.05)$. 
Table 1.Demographic and clinical characteristics of patients.

\begin{tabular}{|l|c|c|c|}
\hline \multicolumn{1}{|c|}{ Variables } & Study Group A (n20) & Control Group B (n20) & P value \\
\hline Age (yearsSD) & $52.9 \pm 6.08$ & $51.25 \pm 6.71$ & 0.42 \\
\hline Height $(\mathrm{cm})$ & $175 \pm 6.43$ & $172 \pm 6.0$ & 0.23 \\
\hline Weight $(\mathrm{Kg})$ & $74.9 \pm 7.75$ & $73.5 \pm 7.15$ & 0.55 \\
\hline Time from stroke onset (month) & $9.6 \pm 1.9$ & $9.45+1.73$ & 0.79 \\
\hline
\end{tabular}

The results of this study regarding to the mean values of overall stability index of postural stability from pre- to post-treatment showed significant improvement in the ability to control balance and minimizing the risk of fall in study groups $(\mathrm{p}<0.05)$ as illustrated in table 2 . Comparing these results between both groups pre-treatment indicated no significant differences. While their comparison post treatment mean improvement scores as elucidated in Tables 2 demonstrated significant differences in favor of the study group $(A)(p<0.05)$.

More illustration, before treatment evaluation revealed that; the mean Overall stability index was (3.82 \pm 0.68$)$ for study group while it was $(2.76 \pm 1.07)$ for control group and there was no significant different between two group as $\mathrm{p}$ value $=(0.1)$.

Post treatment evaluation revealed that; the mean Overall stability index was $(2.4 \pm 0.6)$ for study group while it was $(2.52 \pm 0.80)$ for control group and there was high significant different between post treatment improvement score means of two group as $\mathrm{p}$ value $=(0.003)$ as illustrated in table 2 and figure 6 .

Comparing mean values of OASI within study group revealed that there was high significant differences between before and after treatment mean values as $\mathrm{p}$ value $=(0.002)$, while comparing mean values of OASI within control group revealed that there was no significant differences between before and after treatment mean values as $\mathrm{p}$ value $=(0.32)$ as illustrated in table 2 and figure 5 .

Table (2): Comparisons of means values of Overall stability index within each group and improvement Score means values between groups.

\begin{tabular}{|c|c|c|c|}
\hline \multirow{2}{*}{} & \multicolumn{3}{|c|}{ Overall stability index } \\
\cline { 2 - 3 } & Study Group & Control Group & P value \\
\hline Pre-treatment mean value & $3.82 \pm 0.68$ & $2.76 \pm 1.07$ & $\mathbf{0 . 1}$ \\
\hline Post-treatment mean value & $2.42 \pm 0.78$ & $2.52 \pm 0.80$ & \\
\hline P value & $\mathbf{0 . 0 0 2}$ & $\mathbf{0 . 3 2}$ & $\mathbf{0 . 0 0 3}$ \\
\hline Improvement Score mean & $1.4 \pm 0.42$ & $0.24 \pm 0.47$ & \\
\hline
\end{tabular}

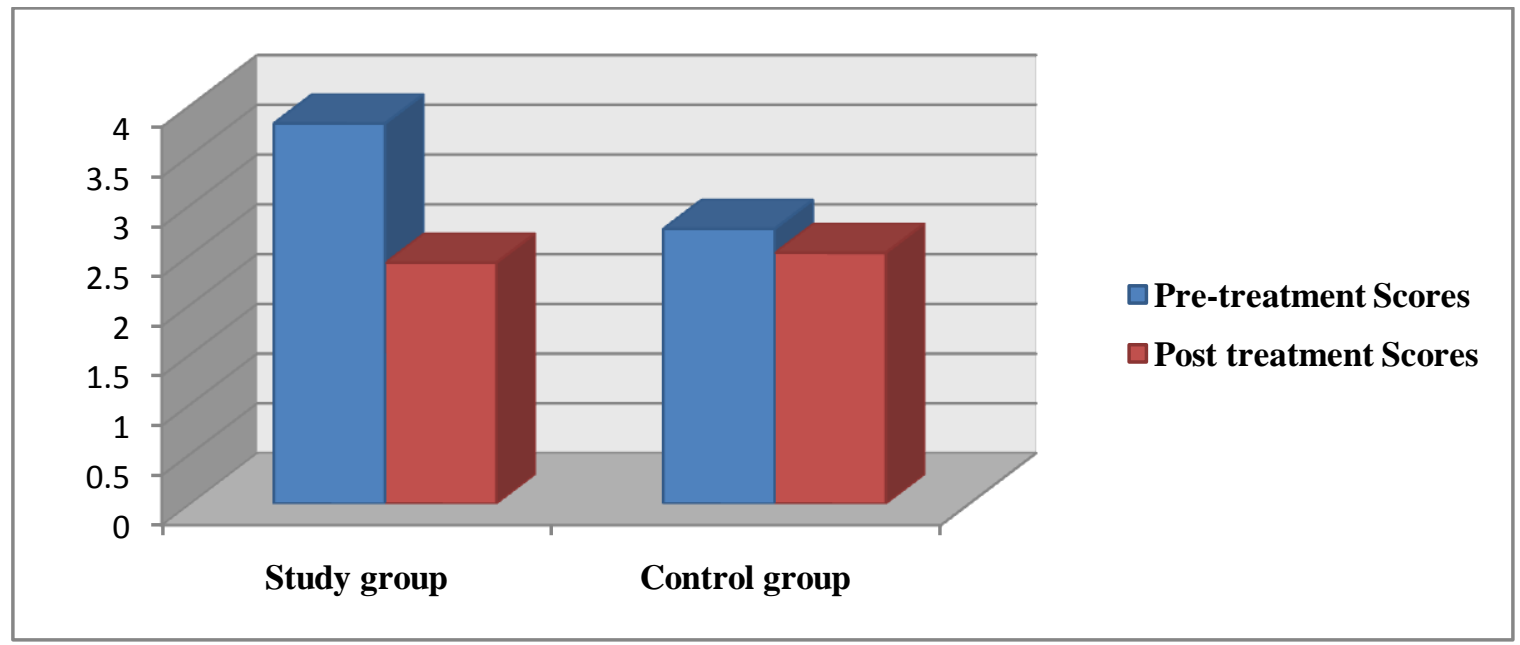

Figure5: Comparisons of mean values of Overall stability index within each group. 


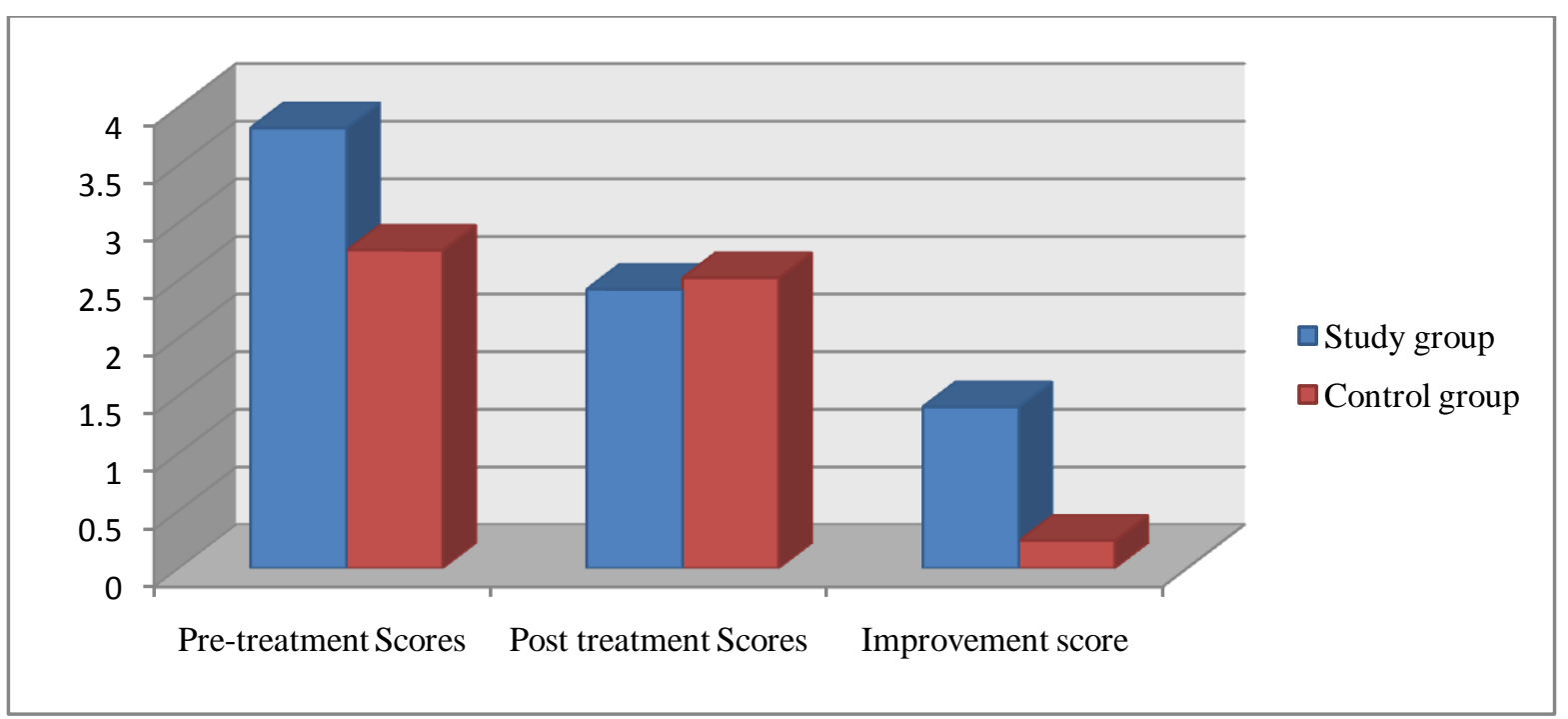

Figure 6: Comparisons of mean values of overall stability and improvement scores between groups.

\section{Discussion:-}

Cerebrovascular disease is an important health problem [15]. After stroke, some patients are unable to stand, and others have higher postural sway, asymmetric weight distribution, impaired weight shifting ability and equilibrium reactions may be delayed or disrupted [16-20]. There is also an increased risk of falling, resulting in high economic costs and social problems [21-23]. Hemiplegia can cause reduction in patient's limits of stability, which are defined as the area where the individual can shift his center of mass without loss of balance and without changing the support base. This describes a theoretical cone extending around a person's feet [24]. Impaired balance greatly influences the activities of daily living (ADL), independence and gait. Therefore, it's essential to rapidly achieve postural control in order to improve independence, social participation and general health .The aim of balance rehabilitation is to ensure safe ambulation [25]. In spite of the multiple therapeutic approaches to promote recovery of postural control, no definitive conclusions can be drawn on which one is the best.

Balance is essential to all functional activities during sitting and standing [26]. Postural control is fundamental to maintain balance. The important resources for postural control are movement strategies, biomechanical constraints, cognitive processing, perception of the verticality (visual and postural), sensory modalities (somatosensory, visual and vestibular) and the sensory reintegration and reweighting in central nervous system (CNS) [27], which can be impaired after a stroke.

Biodex Balance systemis designed to provide visual or auditory feedback to patients regarding the focus of their center-of-pressure (COP). In these systems, feedback is defined as augmented extrinsic information about task success provided to the performer. It's thought that, by giving patients additional information, they will become more aware of the body's displacements and orientation in space. It is believed that the relearning of postural control through external biofeedback is an effective therapy for improving balance control [28]. Hocherman et al. concluded that the hemiplegic patient's stability of stance on a moving platform could be improved by regular training [29].

Shumway-Cook et al. showed that postural sway biofeedback was more effective than conventional therapy in retraining postural stability in hemiplegic patients [30]. In a Cochrane's review of seven randomized controlled trials, Barclay-Goddard et al. concluded that force plate form feedback improved stance symmetry after stroke, without repercussion on postural sway or measures related to gait and independency in ADL [31].

Geiger et al. concluded that combining force platform visual feedback training with conventional physical therapy did not enhance the effects of conventional physical therapy on balance and functional mobility skills in stroke patients with hemiplegia [32]. The present study is designed to assess postural stability, risk of fall and the effect of balance training using biodex training system visual biofeedback among patients with postural disturbances following stroke. Following stroke, postural deficits are common [33]. In the hemiparetic gait there is reduced weight-bearing on the paretic limb [34-36] and excessive postural sway [37, 38]. 
The results of this study show that there is a statistically significant improvement in OASI within study group as well as there is a statistically significant increased OASI improvement scores in study group when compared to those in control group. Postural control is considered to be a prerequisite for restoration of independent living. Sacley et al. studied the effect of the visual feedback after stroke in a randomized controlled trial. They assessed sway and stance symmetry, motor and ADL function at 0, 4 and 12 weeks. They concluded that significant improvements were seen in the treatment group in measures of sway, stance symmetry, motor and ADL function, but differences between groups had disappeared at 3 months [39].

Chen et al. studied the effect of balance training on hemiplegic stroke patients, using 2 groups that received a conventional program. Only the treatment group received visual feedback balance training. They concluded that there were significant improvements of dynamic balance function and ADL function at 6 months of follow-up in the treatment group [40]. Yavuzer et al. studied the effects of balance training on quantitative gait characteristics in a randomized controlled trial. They concluded that balance training using platform biofeedback in addition to a conventional rehabilitation program is beneficial in improving postural control and weightbearing on the paretic side, 6 months after stroke [41]. Like the fore mentioned studies we also found a balance improvement and hence decreased risk of fall in stroke after usingbiodex balance training system.

\section{Conclusion:-}

Balance training using Biodexbalance Systems may increase stability in hemiplegic patient and decrease risk of falling and this may be confirmed when completing the study by more patients involve.

\section{Acknowledgment:-}

The authors wish to thank Institute of Technological Research and Revival associated with Islamic Heritage at Umm Al-Qura University (project \# 43409030) for research project finance and financial support.

Interest conflict:-The author declares that; he has no interest competing.

\section{References:-}

1. Yang, S., Hwang, W.H., Tsai, Y.C., Liu, F.K., Hsieh, L.F. \&Chern, J.S. Improving balance skills in patients who had stroke through virtual reality treadmill training. Am. J. Phys. Med. Rehabil. 2011; 90, 969-978.

2. Kelley, R.E. \&Borazanci, A.P. Stroke rehabilitation. Neurol. Res.2009; 31, 832-840.

3. Belgen B, Beninato M, Sullivan PE, Narielwalla K. The association of balance capacity and falls self-efficacy with history of falling in community-dwelling people with chronic stroke. Arch Phys Med Rehabil 2006; 87:554-61.

4. Graham, J.V., Eustace, C., Brock, K., Swain, E. \& Irwin-Carruthers, S. The Bobath concept in contemporary clinical practice.TopStroke.Rehabil. 2009; 16, 57-68.

5. Geiger RA, Allen JB, O'Keefe J, Hicks RR. Balance and Mobility Following Stroke: Effects of Physical Therapy Interventions with and Without Biofeedback/Forceplate Training. PhyTher 2001; 81: 414-18.

6. Gil-Gomez, J.A., Llorens, R., Alcaniz, M. \&Colomer, C. Effectiveness of a Wii balance board-based system (eBaViR)for balance rehabilitation: a pilot randomized clinical trial inpatients with acquired brain injury. J. Neuroeng. Rehabil.2011; 8, 30.

7. Flansbjer, U.B., Miller, M., Downham, D. \&Lexell, J. Progressive resistance training after stroke: effects on muscle strength, muscle tone, gait performance and perceived participation. J. Rehabil. Med.2008; 40, 42-48.

8. De Oliveira C, De Medeiros I, Frota N, Greters M, Conforto A,. Balance control in hemiparetic stroke patients: Main tools for evaluation. Journal of Rehabilitation Research \& Development. 2008; 45 (8): 1215-1226.

9. Adegoke B, Olaniyi O, Akosile C. Weight Bearing Asymmetry and Functional Ambulation PerformanceIn Stroke Survivors. Global Journal of Health Science, March 2012; DOI: 10.5539/gjhs.v4n2p87.

10. Leroux, A., Pinet, H. \& Nadeau, S. Task-oriented intervention in chronic stroke: changes in clinical and laboratory measures of balance and mobility. Am. J. Phys. Med. Rehabil.2006; 85, 820-830.

11. Karimi N, Ebrahimi I, Kharizi S, Torkaman G. Reliability of postural balance evaluation using the biodex balance system in subjects with and without low back pain. J of Postgraduate Medical Institute.2008;20:2:101316. 
12. Aydog E, Bal A, Aydog ST, Cakei A. Evaluation of dynamic postural balance using the Biodex Stability System in rheumatoid arthritis patients. Clin.Rheumatol.2005; 10:1-6.

13. Wikstrom E, Tillman M, Smith A, and Borsa P.A New Force-Plate Technology Measure of Dynamic Postural Stability: The Dynamic Postural Stability Index.JAthl Train. 2005; 40(4): 305-309.

14. Chun C, Pao-Tsai C, Chia-Ling C, Shih-Ching C, Chia-Ying C, Tu-Hsueh Y. Effects of Balance Training on Hemiplegic Stroke Patients, Chang Gung Med J 2002; 25(9):583-589.

15. Glanz M, Klawansky S, Chalmers T. Biofeedback therapy in stroke rehabilitation: a review. J R Soc Med 1 997;90(1):33-9.

16. Goldie PA, Matyas TA, Evans OM, Galea M, Bach TM. Maximum voluntary weight-bearing by the affected and unaffected legs in standing following stroke.ClinBiomech. 1996; 11(6):333-42.

17. Badke MB, Duncan PW. Patterns of Rapid Motor Responses During Postural Adjustments When Standing in Healthy Subjects and Hemiplegic Patients. Phys Ther1983;47:1020-8.

18. Horak FB, Esselman P, Anderson ME, Lynch MK. The effects of movement velocity, mass displaced, and task certainty on associated postural adjustments made by normal and hemiplegic individuals. J NeurolNeurosurg Psychiatry 1984;47:1020-8.

19. Dickstein R, Abuluflo N. Postural Sway of the Affected and Nonaffected Pelvis and Leg in Stance of Hemiparetic Patients. Arch Phys Med Rehabil 2000;81(3):364-7.

20. Lamb SE, Ferrucci L, Volapto S, Fried LP, Guralnik JM. Women's Health and Aging Study. Risk factors for falling in home dwelling older women with stroke: The Women's Health and Aging Study. Stroke 2003;34(2):494-501.

21. Harris JE, Eng JJ, Marigold DS, Tokuno CD, Louis CL. Relationship of balance and mobility to fall incidence in people with chronic stroke. PhysTher. 2005;85(2):150-8.

22. Belgen B, Beninato M, Sullivan PE, Narielwalla K. The association of balance capacity and falls self-efficacy with history of falling in community-dwelling people with chronic stroke. Arch Phys Med Rehabil 2006;87(4):554-61.

23. McCollum G, Leen TK. Form and exploration of mechanical stability limits in erect stance. J Motor Behav 1989;21:225-44.

24. Geurts AC, de Haart M, van Nes IJ, DuysensJ. A review of standing balance recovery from stroke. Gait Posture 2005;22:267-81.

25. Bonan IV, Yelnik AP, Colle FM, Michaud C, Normand E, Panigot B, Roth P, Guichard JP, Vicaut E. Reliance on visual information after stroke. Part II: Effectiveness of a balance rehabilitation program with visual cue deprivation after stroke: a randomized controlled trial. Arch Phys Med Rehabil 2004;85:274-8.

26. Eser F, Yavuzer G, Karakus D, Karaoglan B. The effect of balance training on motor recovery and ambulation after stroke: a randomized controlled trial. Eur J PhysRehabil Med 2008;44:19-25.

27. Oliveira CB, Medeiros IT, Frota NF, Greters ME, Conforto AB. Balance control in hemiparetic stroke patients: Main tools for evaluation. J Rehabilit Res Dev2008;45(8):1215-26.

28. Walker C, Brouwer BJ, Culham EG. Use of Visual Feedback in Retraining Balance Following Acute Stroke.PhysTher 2000;80:886-95.

29. Hocherman S, Dickstein R. Platform training and postural stability in hemiplegia.ArchPhys Med Rehabil 1984;65:588-92.

30. Shumway-Cook A, Anson D, Haller S. Postural sway biofeedback: its effect on reestablishing stance stability in hemiplegic patients. Arc Phys Med Reahabil 1988;69:395-400.

31. Barclay-Goddard R, Stevenson T, Poluha W, Moffatt ME; Taback, SP. Force platform feedback for standing balance training after stroke. Cochrane Database Syst Rev 2004;18(4):CD004129.

32. Geiger RA, Allen JB, O'keefe J, Hicks RR. Balance and mobility following stroke: effects of physical therapy interventions with and without biofeedback/force plate training. PhysTher 2004;81:995-1005.

33. Dault M, de Haart M, Geurts AC, Arts IM, Nienhuis, B. Effects of visual center of pressure feedback on postural control in young and elderly healthy adults and in stroke patients. Hum MovSci 2003;22(3):221-36.

34. Yavuzer G, Ergin S. Effect of an arm sling on gait pattern in patientswithhemiplegia. Arch Phys Med Rehabil 2002;83:960-3.

35. Wong A, Lee MY, KuoJK , Tang, FT. The Development and Clinical Evaluation of a Standing Biofeedback Trainer. J Rehabil Res Dev 1997;34( 3):322-327.

36. Sacley C. The relationships between weight-bearing asymmetry after stroke, motor function and activities of daily living. Physiotherapy Theory Pract 1990;6:179-85.

37. deHaart M, Geurts AC, Huidekoper SC, Fasotti L, van Limbeek J. Recovery of standing balance in postacute stroke patients: a rehabilitation cohort study. Arch Phys Med Rehabil 2004;85:886-95. 
38. Bonan IV, Colle FM, Guichard JP, Vicaut E, Eisenfisz M, Tran Ba Huy P, YelnikAP. Reliance on visual information after stroke. Part I: Balance on dynamic posturography. Arch Phys Med Rehabil 2004;85:268-73.

39. Sacley CM, Lincoln NB. Single blind randomized controlled trial of visual feedback after stroke: effects on stance symmetry and function. DisabilRehabil 1997;19(12):536-46.

40. Chen IC, Cheng PT, Chen CL, Chen SC, Chung CY, Yeh TH. Effects of Balance Training on Hemiplegic Stroke Patients. Chang Chung Med J 2002;25(9):583-90.

41. Yavuzer G, Eser F, Karakus D, Karaoglan B, Stam HJ. The effects of balance training on gait late after stroke: a randomized controlled trial ClinRehabil. 2006;20(11):960-9. 